\title{
Research Paper: The Toxicity of Synthetic and Biogenic Selenium Nanoparticles on Human Brain Glioblastoma Cell Line: An in vitro Comparison
}

\author{
Shideh Khangholi', Mehdi Mahdavi ${ }^{2,3^{*}}$, Mohammad Hossein Yazdi², 3,4* (D), Ahmad Reza Shahverdi ${ }^{5}$ (i) \\ 1. Department of Microbiology, Pharmaceutical Sciences Branch, Islamic Azad University, Tehran, Iran. \\ 2. Recombinant Vaccine Research Center, Tehran University of Medical Sciences, Tehran, Iran. \\ 3. Immunotherapy Group, The Institute of Pharmaceutical Sciences (TIPS), Tehran University of Medical Sciences, Tehran, Iran \\ 4. Biotechnology Research Center, Faculty of Pharmacy, Tehran University of Medical Sciences, Tehran, Iran. \\ 5. Department of Pharmaceutical Biotechnology, Faculty of Pharmacy, Tehran University of Medical Sciences, Tehran, Iran.
}

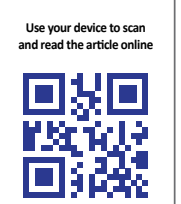

Citation: Khangholi Sh, Mahdavi M, Yazdi MH, Shahverdi AR. The Toxicity of Synthetic and Biogenic Selenium Nanoparticles on Human Brain Glioblastoma Cell Line: An in vitro Comparison. International Journal of Medical Toxicology and Forensic Medicine. 2020; 10(1):26851. https://doi.org/10.32598/ijmtfm.v10i1.26851

doi' https://doi.org/10.32598/ijmtfm.v10i1.26851

Article info:

Received: 27 Aug 2019

First Revision: 02 Sep 2019

Accepted: 05 Sep 2019

Published: 19 Mar 2020

\section{Keywords:}

Selenium, Biogenic Selenium Nanoparticles, Synthetic Selenium Nanoparticles, Human Brain Glioblastoma Cell Line

\section{ABSTRACT}

Background: Brain tumors can be serious and life-threatening when they are treated effectively. Many therapeutic approaches, such as chemotherapy, radiotherapy, and surgery have been used to treat brain tumors. In this regard, selenium supplements have been reported effective.

Methods: Selenium Nanoparticles (SeNPs) were produced in two forms of synthetic and biogenic to evaluate their cytotoxicity on brain glioblastoma cell lines. A-172 cell line was cultured in Dulbecco's Modified Eagle Medium (DMEM) medium. The cytotoxicity of the synthetic and biogenic SeNP was assessed by MTT assay.

Results: There was a significant difference between the group treated with biogenic and synthetic SeNP compared with non-treated cells after 24, 48, and $72 \mathrm{~h}$. Both biogenic and synthetic SeNP increased Bax gene and decreased Bcl-2 gene expression.

Conclusion: It seems that biogenic SeNP was more lethal than its synthetic form. Therefore, it should be considered that the method of NP construction may be an important parameter for its bioactivity.

\section{Introduction}

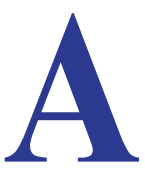

Brain tumor is an abnormal mass of tissue in the brain, which is possibly benign or malignant [1]. Treatment of brain tumors is associated with some side effects.
Therefore, alternative approaches should be considered. Selenium is used as a supplement and has been suggested for cancer prevention [2]. Cancer prevention afforded by selenium is through DNA protection from anti-oxidant substances and regulating cell cycle progression. Also, selenium supplementation can enhance cytotoxic-
* Corresponding Author:

Mehdi Mahdavi, PhD.

Address: Recombinant Vaccine Research Center, Faculty of Pharmacy,

Tehran University of Medical Sciences, Tehran, Iran.

Tel: +98 (912) 6850269

E-mail:mahdavivac@gmail.com
Mohammad Hossein Yazdi, PhD.

Address: Recombinant Vaccine Research Center, Faculty of Pharmacy,

Tehran University of Medical Sciences, Tehran, Iran.

Tel: +98 (21) 66482706

E-mail:mh-yazdi@sina.tums.ac.ir 
ity activity of CD8+T cells against tumor cells [3]. In this regard, it has demonstrated that T cell receptor and IL-2 production is enhanced by selenium in medium culture. Furthermore, it could increase glutathione peroxidase and thioredoxin reductase 1 activity as antioxidants to suppress inflammatory circumstances [4]. It has been shown that the nanostructure of the chemical agents is more bioactive than their oxidative forms. In this regard, selenium nanostructure has found with lower toxicity and higher bioactivity in vitro and in vivo. In this respect, nanotechnology can be used to generate nanomaterials that are c more bioactive [5]. SeNPs can be synthesized by biogenic and synthetic methods. Biogenic NPs could be produced through the utilization of microorganisms, especially bacteria that can convert selenite ion to SeNPs [6]. Synthetic SeNP can be produced in the presence of reducing agents, such as ascorbic acid and lactose. In this condition, selenium dioxide will be reduced and synthetic SeNPs appear in the presence of a reducing agent [7].

This study aimed at investigating the cytotoxicity effect of the biogenic and synthetic SeNPs on the A-172 cell line and its cell death mechanism.

\section{Materials and Methods}

\section{A-172 cell line}

A-172 cell line (human brain glioblastoma) was prepared from the National Cell Bank of Pasture Institute of Iran (Tehran, Iran). The frozen cell sample was defrosted and the cells transferred into the complete Dulbecco's Modified Eagle Medium (DMEM) medium cell culture in an incubator with $5 \% \mathrm{CO}_{2}$ at $37^{\circ} \mathrm{C}$.

\section{Fabrication of the biogenic SeNP}

Biogenic SeNP was produced according to our laboratory framework as reported previously [8]. Briefly, Lactobacillus brevis was cultivated in MRS broth (Mer$\mathrm{ck}$, Germany) at $37^{\circ} \mathrm{C}$ and after overnight incubation, selenium dioxide at a final concentration of $200 \mathrm{mg} / \mathrm{L}$ was added and the culture continued for $72 \mathrm{~h}$. The bacteria suspension was collected by centrifugation at $4000 \times \mathrm{g}$ for $15 \mathrm{~min}$, and the pellet washed three times with PBS buffer. The obtained pellet was disrupted by adding liquid nitrogen and SeNPs were harvested with N-octyl alcohol-water extraction method. Isolated SeNPs were physically characterized for particle size and zeta potential (data are not shown).

\section{Synthetic SeNP preparation}

Synthetic SeNP was produced as reported previously [9]. In brief, selenium dioxide solution $(5.2 \mathrm{mM})$ was prepared and then an aqueous ascorbic acid solution (5.2 $\mathrm{mM}$ ) was slowly added to the selenium solution with continuous stirring at $300 \mathrm{rpm}$. Later, the mixture was centrifuged and the pellet washed three times with double-distilled water. The synthetic SeNPs were characterized physically for particle size and zeta potential (data are not shown).

\section{Toxicity of the biogenic and synthetic SeNPs on} A-172 cell line

Human brain glioblastoma, A-172 cell suspension in complete DMEM medium (Gibco, Germany), was adjusted to $2 \times 105$ cells $/ \mathrm{ml}$. Initially, $100 \mu \mathrm{l}$ of the suspensions containing $2 \times 104$ cells were put in a 96 -well plate (Greiner, Germany) and the biogenic and synthetic SeNPs at the concentrations of 0, 25, 50, 100, 200, 300 and $400 \mu \mathrm{g} / \mathrm{ml}$ were added to the cells at a final volume of $200 \mu \mathrm{l}$ and the plates incubated at $37^{\circ} \mathrm{C}$ with $5 \% \mathrm{CO}_{2}$. The experiments were performed in triplicate and after 24, 48 and $72 \mathrm{~h}$. Cell toxicity was measured by the MTT assay. Briefly, after incubation, $20 \mu \mathrm{l}$ of the MTT solution $(5 \mathrm{mg} / \mathrm{ml}$ in PBS) was added to the wells in dark and the incubation continued for $4 \mathrm{~h}$. The supernatant was then removed carefully and $100 \mu \mathrm{l}$ of DMSO was added to each well to dissolve formazan crystals. The absorbance was measured at $540 \mathrm{~nm}$ by a microplate spectrophotometer (AWARENESS technology, USA).

\section{BCL2 and Bax genes expression}

As mentioned, the cells were treated with biogenic and synthetic SeNPs at IC50 concentration of $100 \mu \mathrm{g} / \mathrm{ml}$ and after 48 and $72 \mathrm{~h}$, cellular RNA was extracted and then cDNA was synthesized using cDNA synthesis Kit (Yekta-Tajhiz, Iran) according to the manufacturer's instruction. Then, $\beta$-actin, BCL 2 and Bax genes expression was evaluated on cDNA samples by a real-time polymerase chain reaction. Beta-actin was utilized as a housekeeping gene to evaluate expression level of BCL2 and Bax genes in the treated glioblastoma cell lines.

\section{Statistical analysis}

The obtained data were analyzed using Graph pad prism V6.01 software. Mann-Whitney U test was applied to compare the significant differences at the significance level of 0.05 . Values are presented as Mean $\pm \mathrm{SD}$. 


\section{Results}

Cytotoxicity of the biogenic SeNP on human brain glioblastoma cell line

Based on the results, treatment with the concentrations of 100,300 , and $400 \mu \mathrm{g} / \mathrm{ml}$ caused significant differences compared with the untreated cells $(\mathrm{P}<0.05)$ (Figure 1A). After $48 \mathrm{~h}$ of biogenic SeNP exposure, cytotoxicity was observed at a concentration of $400 \mu \mathrm{g} / \mathrm{ml}$ compared with untreated cells $(\mathrm{P}=0.0828)$ (Figure 1B). Also, after $72 \mathrm{~h}$ of biogenic SeNP exposure, cytotoxicity was found

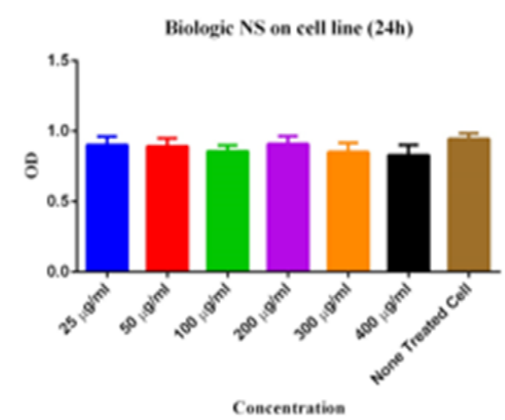

B

Biologic NS on cell line (48h)

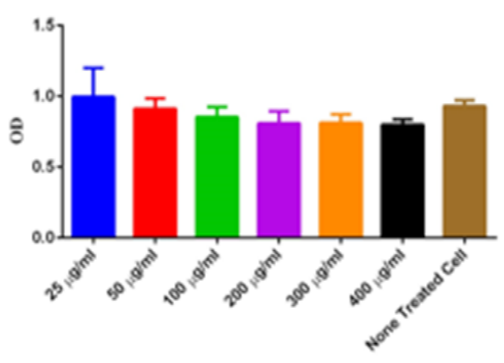

Concentration

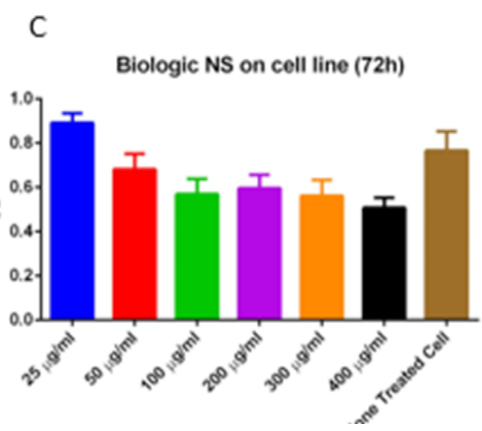

Figure 1. A-172 nervous cell lines

Treated with biogenic SeNP after $24 \mathrm{~h}$ (A), $48 \mathrm{~h}$ (B), and $72 \mathrm{~h}$ (C).

Treated with synthetic SeNP after $24 \mathrm{~h}(\mathrm{D}), 48 \mathrm{~h}(\mathrm{E})$, and $72 \mathrm{~h}(\mathrm{~F})$.

MTT assay was used to measure cytotoxicity. at the concentrations of $25,100,200,300$ and $400 \mu \mathrm{g} / \mathrm{ml}$ than untreated cells $(\mathrm{P}<0.0178)$ (Figure 1C).

Cytotoxicity of the synthetic SeNPs on Human brain glioblastoma cell line

The cells exposed to synthetic SeNPs at $400 \mu \mathrm{g} / \mathrm{ml}$ for 24h showed a significant difference with untreated cells $(\mathrm{P}=0.0021)$ (Figure 1D). There was a significant difference in A-172 cell lines treated with synthetic SeNPs at the concentrations of $100,200,300$, and $400 \mu \mathrm{g} / \mathrm{ml}$ compared with untreated cells after $48 \mathrm{~h}(\mathrm{P}<0.0057)$ (Figure 1E). Also, $72 \mathrm{~h}$ of treatment with synthetic

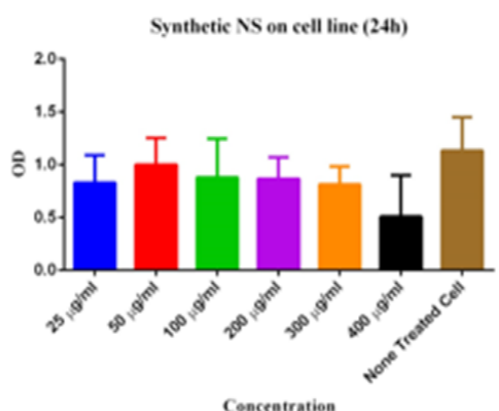

E

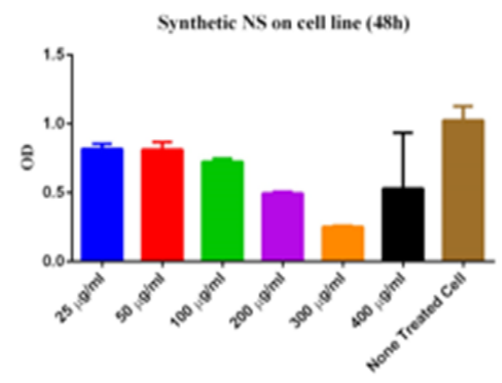

$\mathrm{F}$

Synthetic NS on cell line (72h)

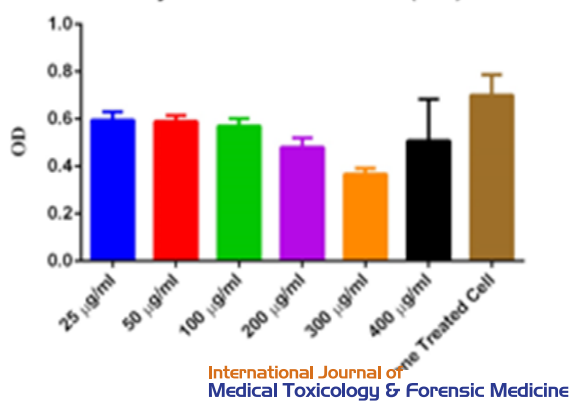



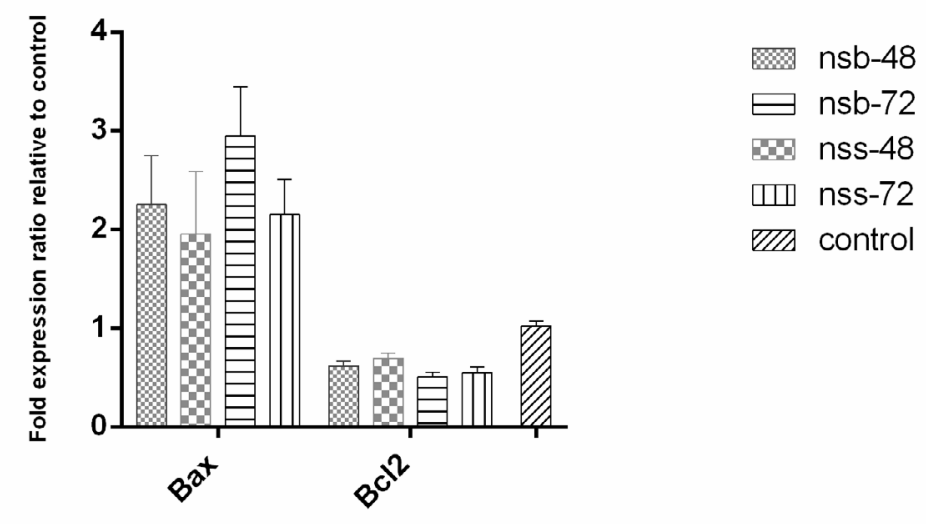

Figure 2. BCL2 and Bax genes expression levels

Evaluated using real-time polymerase chain reaction in A-172 nervous cell lines treated with biogenic and synthetic SeNP after 48 and $72 \mathrm{~h}$.

SeNPs caused a significant difference at the concentrations of $100,200,300$, and $400 \mu \mathrm{g} / \mathrm{ml}$ then untreated cells $(\mathrm{P}<0.0310)$ (Figure 1F).

\section{Results of the BCL2 and Bax Genes expression}

Results showed a 2.25- and 2.95-fold increase in Bax gene expression after 48 and $72 \mathrm{~h}$ of treatment with biogenic SeNP, respectively. Also, after 48 and $72 \mathrm{~h}$ of treatment with synthetic SeNP, a 1.95- and 2.15-fold increase was observed in Bax gene expression in comparison with the control gene expression.

The results indicated 0.651 - and 0.505 -fold increase in BCL2 gene expression in comparison with the control gene expression after 48 and $72 \mathrm{~h}$ of treatment with biogenic SeNP, respectively. Moreover, BCL2 gene expression showed 0.695 - and 0.55 -fold decrease after 48 and $72 \mathrm{~h}$ of treatment with synthetic SeNP, respectively (Figure 2).

\section{Discussion}

SeNP has proved with lower toxicity and higher bioactivity than oxide selenium [10]. Our results showed the toxicity of biogenic SeNP on A-172 cell lines after 24, 48 and $72 \mathrm{~h}$ of treatment. Shamsi et al. study showed the suppression of breast cancer after the treatment of 4T1 cell lines with biogenic SeNP [9]. Faghfuri et al. reported that biogenic SeNP a dose of $200 \mu \mathrm{g}$ caused the most effective responses against tumor cells [8]. A Lactobacillus plantarum strain enriched with biogenic SeNP showed higher IL-12, TNF- $\alpha$ and IFN- $\gamma$ levels and promoted natural killer cells activity in mice model of breast cancer [11]. These findings confirm the anti-tumor effect of biogenic SeNP.

Synthetic SeNP showed cell toxicity effect on tumor cells after 24, 48, and $72 \mathrm{~h}$. The anti-tumor effect of synthetic SeNP has been reported, which is consistent with our results. These findings showed that both derived SeNPs had cell toxicity effect on the human brain glioblastoma cell line. Biogenic and synthetic SeNP increased both Bax and BCL2 genes expression levels after 48, and $72 \mathrm{~h}$. Bax gen, as a pro-apoptotic gene, can eliminate tumor cells by inducing apoptosis pathway and BCL2 inhibits the apoptosis process in tumor cells, which promotes invasion and metastasis in tumor cells $[12,13]$. Therefore, a reduction in BCL2 gene expression in glioblastoma cells and an increase in Bax gene expression indicate the cytotoxicity effect of biogenic and synthetic SeNP on tumor cells. Furthermore, biologic SeNP increased Bax gene expression compared with synthetic SeNP. Therefore, it can be concluded that the cytotoxic potency of biogenic SeNPis more than its synthetic form. The results also showed that treatment length was an undeniable factor in elevating the lethal effect of SeNP.

The biogenic and synthetic forms of SeNP exhibited a drastically killing effect after $72 \mathrm{~h}$ of treatment in comparison with $48 \mathrm{~h}$ of treatment. Kalhori et al. showed that miR579 increased Bax gene expression in glioblastoma cell line and induced apoptotic cell death [14]. Ozawa et al. used radiation therapy for mice harboring brain tumors. The results of the histopathological analysis demonstrated an increase in the level of apoptosis pathway through elevating Bax gene expression [15]. 
As mentioned, other studies have shown the effect of selenium nano-particle on cancer cell line and also they displayed the immuno-stimulatory role of SeNP on cancer cells via arresting cell cycle and promoting $\mathrm{T}$ cell cytotoxicity against tumor cell, therefore, it reinforced immunity, as well.

\section{Conclusion}

Our results demonstrated that biogenic and synthetic SeNP had cytotoxicity effects on A-172 nervous cell line, which is consistent with other studies. However, it seems that biogenic SeNP was more effective than its synthetic form. Therefore, it should be considered that the method of nano-particle construction may be an important parameter for its biological activity.

\section{Ethical Considerations}

\section{Compliance with ethical guidelines}

All ethical principles were considered in this article.

\section{Funding}

This research was supported by a grant from the Deputy of Research of Tehran University of Medical Sciences (Grant No.: 38504).

\section{Author's contributions}

All authors reviewed and contributed to the manuscript prior to submission.

\section{Conflict of interest}

The authors declared no conflict of interests.

\section{Acknowledgements}

We thank Miss Fatemeh Asgar, Mr. Mohammad Mahdi Adib and Mr. Mohammad Mahdi Ghahari for their technical supports.

\section{References}

[1] van Tellingen O, Yetkin-Arik B, de Gooijer MC, Wesseling $\mathrm{P}$, Wurdinger T, de Vries HE. Overcoming the blood-brain tumor barrier for effective glioblastoma treatment. Drug Resistance Updates. 2015; 19:1-12. [DOI:10.1016/j.drup.2015.02.002] [PMID]
[2] Zeng H, Combs GF. Selenium as an anticancer nutrient: Roles in cell proliferation and tumor cell invasion. The Journal of Nutritional Biochemistry. 2008; 19(1):1-7. [DOI:10.1016/j. jnutbio.2007.02.005] [PMID]

[3] Hoffmann PR, Berry MJ. The Influence of selenium on immune responses. Molecular Nutrition \& Food Research. 2008; 52(11):1273-80. [DOI:10.1002/mnfr.200700330] [PMID] [PMCID]

[4] Ren F, Chen X, Hesketh J, Gan F, Huang K. Selenium promotes t-cell response to TCR-stimulation and ConA, but not PHA in primary porcine splenocytes. PLoS One. 2012; 7(4):e35375. [DOI:10.1371/journal.pone.0035375] [PMID] [PMCID]

[5] Fakharzadeh S, Kalanaky S, Hafizi M, Goya MM, Masoumi $Z$, Namaki S, et al. The new nano-complex, Hep-c, improves the immunogenicity of the hepatitis B vaccine. Vaccine. 2013; 31(22):2591-7. [DOI:10.1016/j.vaccine.2013.03.030] [PMID]

[6] Yazdi MH, Mahdavi M, Varastehmoradi B, Faramarzi MA Shahverdi AR. The immunostimulatory effect of biogenic selenium nanoparticles on the 4T1 breast cancer model: An in vivo study. Biological Trace Element Research. 2012; 149(1):22-8. [DOI:10.1007/s12011-012-9402-0] [PMID]

[7] Zhang S-Y, Zhang J, Wang H-Y, Chen H-Y. Synthesis of selenium nanoparticles in the presence of polysaccharides. Materials Letters. 2004; 58(21):2590-4. [DOI:10.1016/j.matlet.2004.03.031]

[8] Faghfuri E, Yazdi MH, Mahdavi M, Sepehrizadeh Z, Faramarzi MA, Mavandadnejad F, et al. Dose-response relationship study of selenium nanoparticles as an immunostimulatory agent in cancer-bearing mice. Archives of Medical Research 2015; 46(1):31-7. [DOI:10.1016/j.arcmed.2015.01.002] [PMID]

[9] Molanouri Shamsi M, Chekachak S, Soudi S, Quinn LS, Ranjbar K, Chenari J, et al. Combined effect of aerobic interval training and selenium nanoparticles on expression of IL-15 and IL-10/TNF-a ratio in skeletal muscle of $4 \mathrm{~T} 1$ breast cancer mice with cachexia. Cytokine. 2017; 90:100-8. [DOI:10.1016/j. cyto.2016.11.005] [PMID]

[10] Mahmoudvand H, Shakibaie M, Tavakoli R, Jahanbakhsh S, Sharifi I. In vitro study of ILeishmanicidal activity of biogenic selenium nanoparticles against Iranian isolate of sensitive and glucantime-resistant leishmania tropica. Iranian Journal of Parasitology. 2014; 9(4):452-60.

[11] Yazdi MH, Mahdavi M, Kheradmand E, Shahverdi AR The preventive oral supplementation of a selenium nanoparticle-enriched probiotic increases the immune response and lifespan of $4 \mathrm{~T} 1$ breast cancer bearing mice. Arzneimittelforschung. 2012; 62(11):525-31. [DOI:10.1055/s-0032-1323700] [PMID]

[12] Alam M, Kashyap T, Mishra P, Panda AK, Nagini S, Mishra R. Role and regulation of proapoptotic Bax in oral squamous cell carcinoma and drug resistance. Head \& Neck 2019; 41(1):185-97. [DOI:10.1002/hed.25471] [PMID]

[13] Hedayat M, Mahmoudi MJ, Rose NR, Rezaei N. Proinflammatory cytokines in heart failure: Double-edged swords. Heart Failure Reviews. 2010; 15(6):543-62. [DOI:10.1007/ s10741-010-9168-4] [PMID]

[14] Kalhori M, Irani S, Soleimani M, Arefian E, Kouhkan F [Effect of miR-579 overexpression on the BAX and CDKN1A 
genes in the Glioblastoma cell line. Pathobiology Research (Persian)]. 2019; 22(1):27-34.

[15] Ozawa T, Hu JL, Hu LJ, Kong EL, Bollen AW, Lamborn KR, et al. Functionality of hypoxia-induced BAX expression in a human glioblastoma xenograft model. Cancer Gene Therapy. 2005; 12(5):449-55. [DOI:10.1038/sj.cgt.7700814] [PMID] 